\title{
Methamphetamine use and sexual risk behaviour in Cape Town, South Africa: A review of data from 8 studies conducted between 2004 and 2007
}

\author{
CDH Parry',2, A Plüddemann', B Myers', WM Wechsberg', AJ Flisher \\ ${ }^{1}$ Alcohol \& Drug Abuse Research Unit, Medical Research Council, South Africa \\ 2Department of Psychiatry Stellenbosch University, South Africa \\ ${ }^{3}$ Substance Abuse Treatment Evaluation \& Intervention Research Program, RTI International, USA \\ ${ }^{4}$ Department of Psychiatry \& Mental Health, University of Cape Town, South Africa
}

\begin{abstract}
Objective: Community studies and studies of admissions to drug treatment centers indicate a dramatic increase in the prevalence of methamphetamine use in Cape Town since 2003. There has also been a substantial increase over this time period in the prevalence of HIV infection among women attending public antenatal clinics in the Western Cape province. This study aimed to review research conducted in Cape Town on the link between methamphetamine use and sexual risk behaviour. Method: A review of published research conducted in Cape Town between 2004 and 2007 was undertaken using PubMed, EBSCOhost and Science Direct. Results: Eight studies were identified, both quantitative and qualitative, and focusing on diverse populations, such as learners in school, out of school youth, adults in the community, men who have sex with men and sex workers. The total sample across the studies was 8153. Across multiple studies methamphetamine was fairly consistently associated with early vaginal sex, condom use during sex, having casual sex and other HIV risk behaviours. For some sub-groups the direction of the relationship was in an unexpected direction. Conclusion: The consistency of the findings across studies highlights the increased risk for contracting HIV among methamphetamine users, and reinforces the importance of interventions addressing both methamphetamine use and unsafe sexual behaviour among young people and other sectors of the population. The need for further research is also considered, particularly research that will explain some of the racial differences that were found.
\end{abstract}

Keywords: Methamphetamine; Sexual behaviour; HIV; South Africa

Received: 17-12-2010

Accepted: 1 1-03-201 1

doi: http://dx.doi.org/10.4314/ajpsy.v14i5.4

\section{Introduction}

Recent community studies, school surveys and studies of admissions to drug treatment centres have all reported extremely high levels of methamphetamine (MA) use in Cape Town. For example, in a study conducted in a Cape Town township and its surrounding informal settlements, $11 \%$ of men and $6 \%$ of women reported using $\mathrm{MA}$ in the previous six months ${ }^{1}$, and lifetime prevalence of MA use among high school learners in the city was found to range between $9 \%$ and $12 \%{ }^{2,3}$ In specialist substance

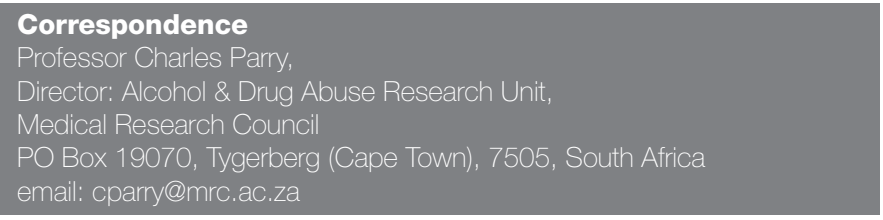

abuse treatment centres in greater Cape Town, the proportion of patients reporting MA as their primary or secondary drug of abuse increased significantly from $0.7 \%$ in the first half of 2002 to $52 \%$ in the second half of 2006 and then reduced slightly to $47 \%$ in the second half of 2009. ${ }^{4}$ In the latter six month data collection period, $57 \%$ of the patients treated with MA as a primary drug of abuse were aged between 15 and 24 years of age, 51\% reported daily use, and 99\% reported smoking the drug. ${ }^{4}$ The Western Cape Province, which has Cape Town as its capital, has also seen a dramatic increase in the prevalence of HIV infection among women attending public antenatal clinics (and in the population in general). In the 2009 antenatal clinic HIV survey, for example, 16.9\% of women attending public antenatal clinics were found to be HIV positive, compared to only $0.1 \%$ in $1990 .{ }^{5}$

MA (known locally as "tik" because of the noise made when it is heated in a glass tube) is a long-acting stimulant. In South Africa, it is 
usually smoked. It is inexpensive (US\$4 per straw) and widely available. International research has shown that use of this drug enhances sexual desire. ${ }^{6,7}$ It has also been associated with high levels of sexual risk behaviour, including unprotected sex, multiple partnering, and anal sex. ${ }^{8}$

In conclusion, there is a high and increasing prevalence of HIV in this part of South Africa, resulting mainly from an epidemic driven by heterosexual transmission ${ }^{9}$; there is also a high demand for substance abuse treatment for MA-related problems, which is indicative of high levels of use in the community; and there is evidence for an effect of MA use on sexual risk behaviour. We thus decided to investigate the linkage between MA use and sexual risk behaviour among drug user groups in Cape Town. The specific aims of the study were to: (i) review research conducted in Cape Town between 2004 and 2007 on the link between MA use and sexual risk behaviour, (ii) summarise the key findings of these studies, and (iii) identify areas for further research.

\section{Methods}

A review of published research conducted in Cape Town between 2004 and 2007 was undertaken using PubMed, EbscoHost and Science Direct. Key words in the search included "methamphetamine", "HIV", "AIDS", "sexual risk behavior (or behaviour)", and "Cape Town". The methodology for each study was summarized and key findings investigated to assess the impact of methamphetamine on various sexual risk behaviours. Findings were summarised in tabular format.

\section{Results}

Seven cross-sectional studies (five quantitative and two and qualitative) were identified using the search strategy. A further "in press" study by one of the authors (AP) was also identified, even though it will only show up on the PubMed database in 2011 . These focused on diverse populations, such as learners in school (2 studies), out of school youth (1), and adults in the community (5), including men who have sex with men and sex workers (Table I). Coloured and Black African participants were over-represented in the populations studied. (The terms, "white", "Black African" (Bl), and "Coloured" (Col), originate from the apartheid era. They refer to demographic markers and do not signify inherent characteristics Their continued use in South Africa is important for monitoring improvements in health and socio-economic disparities, identifying vulnerable sections of the population, and planning effective intervention programmes that target vulnerable groups.)

\section{Study 1}

In this 2005 school survey ${ }^{2}$ of a representative sample of 4605 grade 9 students in Cape Town, high school students who had used MA in the past 30 days (5.1\% of males and 3.2\% of females) were significantly more likely than students who had never used MA to have had vaginal sex (56.7\% [95\% CI: 48.0-64.9] vs $22.8 \%$ [17.329.4]), had oral sex (43.1\% [34.5-52.2] vs 14.6\% [12.1-17.6]), had anal sex (40.7\% [32.5-49.5] vs 12.9\% [9.3-17.7]), made a girl pregnant or been pregnant (17.6\% [1 1.6-25.7] vs 2.5\% [1.7-3.5]), or had a sexually transmitted infection (STI) (30.5\% [20.0-43.4] vs $10.7 \%$ [7.4-15.2]).

\section{Study 2}

Another school survey ${ }^{3}$ was conducted in 2006 among a representative sample of 1561 students in grades 8-10 in high schools in the South Educational District of Cape Town. Compared to high school students who had used drugs other than MA in their lifetime, lifetime MA users (8.8\% of the students) were significantly more likely to have had sex (45.3\% [95\% CI: 36.8-53.7] vs 16.4\% [12.7-20.0]) and if so, to have been intoxicated when having sex (50.0\% [37.2-62.8] vs 15.4\% [6.4-24.4]). There was no significant difference between lifetime users of MA and lifetime users of other drugs on whether they ever had sex without a condom (71.0\%

\begin{tabular}{|c|c|c|c|c|c|c|c|c|c|}
\hline Study & Year & Type & Sampling (N) & Procedure & Mean age & $\%$ female & Race* $^{\star}$ & $\begin{array}{l}\text { Location within } \\
\text { Cape Town }\end{array}$ & $\begin{array}{l}\text { Prevalence MA } \\
\text { use (period) }\end{array}$ \\
\hline 1 & 2005 & Quantitative & Multi-stage, 30 schools $(n=4605)$ & Self completed (PDAs) & 15.3 & 54 & All & $\begin{array}{l}\text { All state school } \\
\text { in city }\end{array}$ & $\begin{array}{l}13.3 \% \mathrm{~m}, 11.9 \% \mathrm{f} \\
\text { (lifetime) }\end{array}$ \\
\hline 2 & 2006 & Quantitative & Multi-stage, 15 schools ( $n=1561$ ) & Self completed (PDAs) & 14.9 & 53 & All & $\begin{array}{l}\text { All state schools } \\
\text { (S Ed. District) }\end{array}$ & $10 \%, 8 \%$ f (lifetime) \\
\hline 3 & 2006 & Quantitative & $\begin{array}{l}\text { Convenience-out of school drug } \\
\text { users ( } n=449 \text { ) }\end{array}$ & Interview & 16.8 & 100 & $\mathrm{Col}, \mathrm{Bl}$ & 10 communities & $\begin{array}{l}11 \%(\mathrm{Bl}), 87 \% \\
\text { (Col) (current use) }\end{array}$ \\
\hline 4 & 2005 & Quantitative & $\begin{array}{l}\text { Convenience- poor drug users } \\
\text { (113) }\end{array}$ & Interview & 26.0 & 100 & Col, Bl & $\begin{array}{l}\text { Langa, Gugulethu, } \\
\text { Khayalitsha, M'Plain }\end{array}$ & $\begin{array}{l}46.5 \%(\mathrm{Col}) \\
\text { (current use) }\end{array}$ \\
\hline 5 & 2004 & Quantitative & $\begin{array}{l}\text { Convenience, street intercepts } \\
(\mathrm{n}=962)\end{array}$ & Interviews & Adult & 54 & Col, Bl & $\begin{array}{l}\text { Delft, Khayalitsha, } \\
\text { M'Plain }\end{array}$ & $18 \% \mathrm{~m}, 12 \% \mathrm{f}$ \\
\hline 6 & $2006-7$ & Quantitative & Convenience, snowballing ( $n=339)$ & Interview & Adult & 73 & All & $\begin{array}{l}\text { Undisclosed } \\
\text { township }\end{array}$ & $\begin{array}{l}11 \% \text { (past } \\
3 \text { months) }\end{array}$ \\
\hline 7 & 2005 & Qualitative & $\begin{array}{l}\text { Convenience, snowballing } \\
\text { (CSW, MSM, IDUs, NIDUs) (n=90) }\end{array}$ & Interview & Adult & 36 & All & $\begin{array}{l}\text { Woodstock, Salt River, } \\
\text { Sea Point, Green Point }\end{array}$ & $60 \%$ (current use) \\
\hline 8 & 2005 & Qualitative & Convenience $(n=33)$ & Focus Groups & Adult & 0 & Col, Bl & M' Plain, Langa & 48\% (current use) \\
\hline
\end{tabular}


[59.3-82.6] vs 47.7\% [35.2-60.2]), had sex with two or more people in the past three months (30.6\% [18.8-42.4] vs 13.8\% [5.2-22.5]), had used a condom the last time they had sex (54.8\% [42.1-67.6] vs $55.4 \%$ [43.0-67.8]) or had talked to their partners about using a condom during sex (56.5\% [43.8-69.1] vs 66.2\% [54.3-78.0]).

\section{Study 3}

In a 2006 study of 449 young Coloured and Black African out-ofschool drug users surveyed in 10 lower income communities in Cape Town ${ }^{10}$, Coloured females who had used MA in the past 30 days $(84.6 \%, \mathrm{n}=176)$ were significantly more likely than Coloured females who used drugs other than alcohol, tobacco and MA ( $\mathrm{n}=32)$ to have had sex before the age of 15 years (77.8\% [95\% CI: $72.0-$ 84.0] vs 56.3\% [39.0-73.0]), to ever have had sex without a condom (63.1\% [56.0-70.0] vs 37.5\% [21.0-54.0]), to have had multiple partners in the past 90 days (50.6\% [43.0-58.0] vs $21.9 \%$ [8.0-36.0]), to have had sex with someone five or more years older than them (36.9\% [30.0-44.0] vs 12.5\% [1.0-24.0]), and were significantly less likely to have used a condom the last time they had sex (59.1\% [52.0-66.0] vs 84.4\% [72.0-97.0]). No statistically significant differences were found between Coloured users of MA in the past 30 days and those who had used other substances on whether they had ever been forced to have sex (13.1\% [8.0-18.0] vs 3.1\% [0.09.0]), whether they had STI symptoms in the previous 12 months (14.2\% [9.0-19.0] vs 15.6\% [3.0-28.0]), whether they have ever had sex while intoxicated (78.4\% [72.0-84.0] vs 59.4\% [42.0-76.0]), and whether they have ever had anal sex (7.4\% [4.0-1 1.0] vs 3.1\% [0.09.0).

Compared to young Black African out-of-school females who used drugs other than alcohol, tobacco and MA in the past 30 days ( $\mathrm{n}=150)$, Black African females who had used MA (10.2\%, n=17) were significantly less likely to have had STI symptoms in the previous 12 months (35.3\% [95\% CI: 13.0-58.0] vs 54.0\% [46.062.0]), or to have had sex with someone five or more years older than them (17.6\% [0.0-36.0] vs 52.7\% [45.0-61.0]). No statistically significant differences were found between Black African users of MA and those who had used other substances on whether they had sex before the age of 15 years (76.5\% [56.0-97.0] vs 76.0\% [69.083.0]), ever had sex without a condom (76.5\% [56.0-97.0] vs $82.7 \%$ [77.0-89.0]), ever had sex while intoxicated (47.1\% [23.0-71.0] vs $56.7 \%$ [49.0-65.0]), had multiple partners in the past 90 days ( $17.6 \%$ [0.0-36.0] vs 26.0\% [19.0-33.0]), had used a condom the last time they had sex (70.6\% [49.0-92.0] vs 58.0\% [50.0-66.0]), had ever been forced to have sex (35.3\% [13.0-58.0] vs 26.0\% [19.0-33.0]), and whether they have ever had anal sex (17.6\% [0.0-36.0] vs $15.3 \%$ [10.0-21.0]).

\section{Study 4}

In a pilot intervention study of 113 Black African and Coloured drug using women from four townships in Cape Town undertaken in $2005^{11}$, poor, females who had used MA in the past 30 days (43.1\%) were significantly less likely than poor females who had used other drugs to have had sex under the influence of alcohol or other drugs in the past 30 days (10.6\% [95\% CI: 3.6-23.1] vs 46.8\% [34.0-59.9]) and significantly more likely to have used a condom during last vaginal intercourse (80.0\% [65.4-90.4] vs 54.8\% [41.7-67.5]\%). No statistically significant differences were found between the women who used MA in the past 30 days and those who used other drugs in terms of whether they had multiple partners in the past 30 days (5.0\% [7.0-31.5] vs 16.7\% [1.0-13.9]), had ever had STIs [4.4\% [0.5$15.2]$ vs $3.2 \%$ [0.4-11.2), had traded sex to get money in the past 30 days (0.0\% [0.0-7.7] vs 3.4\% [0.4-11.7]), or had traded sex to get drugs in the past 30 days (0.0\% [0.0-7.7] vs 1.7\% [0.0-9.1]). Some of the data presented above were not included in the published paper but from additional information available to two of the authors who were also authors on this paper (WW,CP)

\section{Study 5}

A quantitative study of Black African and Coloured participants in three communities in Cape Town conducted in 2004 used street intercepts sampling to interview 962 adults. ${ }^{12}$ Compared to drug users who had not used MA, persons who had used MA in the past 6 months (11\% of males and 6\% of females) were significantly more likely to have ever received money or goods in exchange for sex (16\% vs 5\%, Odds Ratio (OR)=3.2, 95\% CI: 1.2-8.6]), to have had three or more sexual partners in the past six months (45\% vs 15\%, Adjusted Odds Ratio (AOR)=2.5, 95\% CI: 1.8-3.5), to have had multiple partners and unprotected sex in the past six months (53\% vs 18\%, AOR=6.2, 95\% CI: 3.1-12.3), and to have had sex involving alcohol (57\% vs 45\%, AOR=2.4, 95\% CI: 1.3-4.6). No significant difference was found between MA users and non-MA users in terms of having ever having had an STI (16\% vs 18\%, OR=1.2, 95\% CI: 0.62.5).

\section{Study 6}

In a study of 339 persons recruited via snowball sampling at four shebeens (informal, unlicensed liquor outlets) in a township in Cape Town between 2006 and $2007^{13}$, persons who had used MA in the past three months (1 1\%) were significantly more likely to have met their sex partner at a shebeen than persons who had not used MA in the past three months (18\% vs 8\%. OR=2.5, 95\% CI: 1.2-5.1).

\section{Study 7}

In late 2005 a rapid assessment of drug users in four suburbs of Cape Town was undertaken via 50 key informant interviews and focus group interviews with 40 drug users. ${ }^{14}$ Interviewees comprised drug using street commercial sex workers (CSWs), drug using men who have sex with men (MSM), and injection and noninjection drug users (IDUs/NIDUs) who were not CSWs or MSM. From the qualitative interviews MA was found to be associated with sex and sexual risk. It was described as a "high sex" drug - the drug most associated with sexual activity by CSWs, a drug that makes a person "horny". CSWs indicated that it makes them want to have sex and feel like they are not selling their bodies, but that they desire sex with their clients: One MSM talking about MA stated that: "Drugs 'turn you on' and 'relaxes' you for sex and it not only enhances the sexual experience but also the sexual 'drive'." Drugs are thought to prolong sex sessions: "And if you sex, you cannot stop... Because it takes a long time to come. Maybe two, three hours" (21 year old, Cape Town).

\section{Study 8}

In 2005 four focus group interviews were undertaken with a total sample of 33 men in two suburbs of Cape Town, Mitchell's Plain and Langa. ${ }^{15}$ The participants were selected via convenience and snowball sampling techniques. Eligibility criteria included being a male living in Cape Town or one of the targeted settlement areas; being self-identified as Black African or Coloured; having had more than one sex partner in the past 90 days; use of alcohol, cannabis, methaqualone, cocaine, heroin, glue, Ecstasy, MA or LSD on at least 13 of the past 90 days and being at least 18 years old; and being able to understand English. Men in both of the Coloured groups 
( $n=15)$ spoke about a gang rape situation where one man would go out with a woman and get her high. He will then inform his friends when she goes to sleep after coming down off a MA-induced high and they will take turns to rape her. In such situations some men use a condom while many do not. The fact that she is a drug user appears to mitigate their feelings of having done anything wrong. Some men specifically referred to using condoms with "tik monsters" (women who will do anything for a hit of MA) whereas other did not seem to care.

Table II provides a summary of the findings (across the 8 studies). While not all 14 of the risk behaviours that increase the risk of contracting HIV were investigated in each of the 8 studies, there does appear to be some consistency for some of the risk behaviours. For example, MA use was fairly consistently associated with early vaginal sex (3 studies), condom use during sex (4), and having casual sex (2). Mixed findings were noted for the association between MA use and anal sex (with one study in young people finding a significant association while another with out of school females did not. Mixed findings were also noted for the association between STI symptoms and MA use, having multiple partners and MA use (with three studies finding an association and two not) and methamphetamine and forced sex. Some of the findings were not in the same direction across studies (e.g. the association between MA and use of drugs when having sex, use of MA and STI symptoms, having sex without a condom, and having sex with a substantially older person).

\section{Discussion}

The combined research findings covered in this review add to the literature on the link between MA use and sexual risk behaviour (HIV risk) among heterosexual drug users. It also provides information on the younger population of MA users than is typically studied in other countries. From a local perspective it highlights a range of different mechanisms through which MA use is associated with sexual risk behaviours known to be linked to HIV transmission.

The finding that MA use facilitates sexual transmission behaviours has been shown previously in US populations, both in heterosexual men and women and among MSM. ${ }^{8}$ Research among heterosexual populations has, for example, shown that MAdependent users have more sexual partners and participate in more risky sexual behaviour (i.e. no condom use and anal sex) than persons who use other drugs. ${ }^{7,8}$ The analysis of the findings from the eight studies conducted in Cape Town, however, found less consistent findings of an association between MA use and having sex without a condom, with several studies indicating an association ${ }^{10,11,12,15}$ and others not. $3,10,15$ The one study which found that MA use was more associated with condom use ${ }^{11}$, also found that MA users were less likely to have sex under the influence of alcohol or other drugs in contrast to three studies that found the opposite. ${ }^{3,13,15}$ In the former study, 45 of the $47 \mathrm{MA}$ users were Coloured and only two were Black African, whereas only 7 of the non-MA users were Coloured and 55 were Black African. It is likely that the findings were influenced by the higher numbers of non-MA using Black African women, many of whom were already engaging in high risk behaviours.

The findings of Study $3^{10}$ that Black African MA-using women were less likely than non-MA users to have STI symptoms or to have sex with someone five or more years older may have partly been influenced by the skewed distribution of the data. This may also be influenced by higher levels of HIV risk among young Black African women compared to Coloured women prior to or apart from any particular substance use. ${ }^{16}$ In this study only 17 of the 167 Black African women had used MA in the past 30 days. ${ }^{10}$ The implication is that in Black African communities with already high levels of sexual risk behaviour, among women at least, MA use does not increase certain sexual risk behaviours and if anything is indicative of lower levels of risk. In this study for Black African women sex with someone five or more years older was not significantly associated Table II: Summary of findings across the 8 studies where statistically significant findings for methamphetamine users vs other
drug using populations were noted

\begin{tabular}{|c|c|c|c|c|c|c|c|c|}
\hline \multirow[t]{2}{*}{ HIV risk behaviour } & \multicolumn{8}{|c|}{ Study } \\
\hline & 1 & 2 & 3 & 4 & 5 & 6 & 7 & 8 \\
\hline $\begin{array}{l}\text { Early vaginal sex } \\
\text { Oral sex } \\
\text { Anal sex } \\
\text { Made/been pregnant } \\
\text { STI symptoms } \\
\text { AODs when having sex } \\
\text { Multiple partners } \\
\text { Sex without condom } \\
\text { Trade sex for drugs } \\
\text { Casual sex } \\
\text { Arousal (if not too much) } \\
\text { Prolonged sex } \\
\text { Forced sex } \\
\text { Sex with someone } 5 \text { or more years older }\end{array}$ & $\begin{array}{l}p<0.05 \\
p<0.05 \\
p<0.05 \\
p<0.05 \\
p<0.05 \\
- \\
- \\
- \\
- \\
- \\
- \\
- \\
-\end{array}$ & $\begin{array}{l}p<0.05 \\
- \\
- \\
- \\
- \\
p<0.05 \\
n s \\
n s \\
- \\
- \\
- \\
- \\
- \\
-\end{array}$ & $\begin{array}{l}p<0.05(\mathrm{Col}) \mathrm{ns}(\mathrm{Bl}) \\
\text { ns } \\
\text { ns (Col) }(p<0.05)(\mathrm{Bl}) \\
\text { ns } \\
p<0.05(\mathrm{Col}) \mathrm{ns}(\mathrm{Bl}) \\
p<0.05(\mathrm{Col}) \mathrm{ns}(\mathrm{Bl}) \\
\text { ns } \\
p<0.05(\mathrm{Col})(p<0.05)(\mathrm{Bl})\end{array}$ & $\begin{array}{l}- \\
- \\
- \\
\text { ns } \\
(p<0.05) \\
\text { ns } \\
(p<0.05) \\
\text { ns } \\
- \\
- \\
- \\
-\end{array}$ & $\begin{array}{l}- \\
- \\
- \\
- \\
n s \\
p<0.01 \\
p<0.01 \\
p<0.01 \\
p<0.01 \\
- \\
- \\
- \\
-\end{array}$ & $\begin{array}{l}- \\
- \\
- \\
- \\
- \\
- \\
- \\
- \\
- \\
p<0.05 \\
- \\
- \\
- \\
-\end{array}$ & $\begin{array}{l}- \\
- \\
- \\
- \\
- \\
\text { Noted } \\
- \\
\text { Noted } \\
\text { Noted } \\
\text { Noted } \\
\text { Noted } \\
- \\
-\end{array}$ & $\begin{array}{l}\text { Noted } \\
\text { Noted } \\
\text { Varied (Col) } \\
\text { Noted } \\
\\
\text { Noted (Col) }\end{array}$ \\
\hline
\end{tabular}

p-values $<0.05$ or $<0.01$ signify statistically significant findings. "ns"- refers to not statistically significant. If the p-value is indicated in brackets this signifies that the statistical significance is in the direction opposite to that expected. (Bl)-Black African, (Col)-Coloured indicate that the association was only significant for one subgroup in the population or that the direction of the association differed between subgroups. In the case of studies 7 and 8, as they involved qualitative research, saturation is present is indicated as 'Noted'. AOD refers to alcohol and other drugs 
with MA use whereas for Coloured females it was. This could also be related to the fact that in this population group having sex with older men is not uncommon and is associated with exchanging sex for money and goods, being raped, or even as a consequence of the myth that having sex with a virgin can cure AIDS. Obviously the role of MA use among black African women's sexual behaviours needs much more investigation- especially as sample size in this study is so small.

In terms of limitations, because of the design of the individual studies, it is difficult to assess whether MA use causes risky sexual behaviour or whether there might be other factors at play, such as people with more risk taking personalities being more likely to use MA. Due to the small number of studies found (6 quantitative studies) no meta-analytic techniques were employed.

The findings presented highlight the need for further research particularly focusing on (i) the effects of using MA in combination with other drugs (including "downers" such as heroin and methaqualone which are both commonly used in Cape Town) ${ }^{4}$ on sexual risk behaviour, (ii) the specific causal linkages through which MA use affects sexual risk behaviour (e.g. does it affect the efficacy of condom use and not just use per se, and the choice of sexual partners), (iii) the effect of different quantities of MA consumed, and (iv) and possible gender differences. Given the small numbers of Black African MA users in some of the studies, more research is also needed to explain why MA use seemed to indicate lower sexual risk behaviour in some of the Black African populations studied. Other local studies are needed to see if the positive associations found in single studies reviewed here between MA use and prolonged sex, arousal, oral sex (among high school student), being pregnant (among high school student), and having forced sex are supported. In addition, an answer to the question of whether a person's knowledge of their own HIV positive status or the psychological/psychiatric sequelae of HIV could contribute to increased MA use, also needs to be obtained.

This review has implications for prevention and other interventions for both MA use and HIV-risk, especially among the Coloured population of the Western Cape which currently have relatively lower rates of HIV (although increasing incidence levels) ${ }^{16}$ and where MA use could act as another vector for rapid spread of epidemic. In particular HIV prevention and treatment programmes addressing sexual behaviour should also address MA (and other drug) use. Conversely substance abuse prevention and treatment programmes should also focus on drug-related HIV risk behaviour fuelled by drug use. The focus should be on development comprehensive, integrated programmes for addressing drugrelated sexual risk behaviour. ${ }^{17}$

\section{Conclusions}

The consistency of the findings across most studies highlights the increased risk for contracting HIV among MA users in a part of the world with an already increasing prevalence of HIV, and highlights the need for interventions targeted at young people and other sectors of the population. It also highlights the need for research to explain some of the racial differences that were noted in this study.

\section{Acknowledgements}

This review was not supported by any funder, but the studies reported on were funded by the European Union, the US Centers for Disease Control and Prevention (CDC)/US, and the US President's
Emergency Plan for AIDS Relief (PEPFAR), and the National Institute on Drug Abuse (NIDA). Its contents are solely the responsibility of the authors and do not necessarily represent the official views of these funders.

\section{References}

1. Simbayi LC, Kalichman SC, Cain D, Cherry C, Henda N, Cloete A. Methamphetamine use and sexual risks for HIV infection in Cape Town, South Africa. J Subs Use 2006; 11: 291-300.

2. Plüddemann A, Flisher AJ, Mathews C, Carney T, Lombard C. Adolescent methamphetamine use and sexual risk behaviour in secondary school students in Cape Town, South Africa. Drug Alcohol Rev 2008; 27: 687-692

3. Plüddemann A, Flisher AJ, McKetin R, Parry CDH, Lombard C. Methamphetamine use and sexual risk behaviors among high school students in Cape Town, South Africa. J Child Adolesc Subst Abuse 2011.

4. Plüddemann A, Dada S, Parry C, Bhana A, Perreira T, Nel E, Mncwabe T, Gerber W, Aboagye L. Monitoring alcohol and drug abuse trends in South Africa (July 1996 - December 2009). SACENDU Research Brief 2010, 13: 1-12.

5. Department of Health. National antenatal sentinel HIV and syphilis prevalence survey in South Africa, 2009. Pretoria: Author.

6. Semple SJ, Patterson TL, Grant I. The context of sexual risk behaviour among heterosexual methamphetamine users. Addict Behav 2004; 29: 807810.

7. Rawson RA, Washton A, Domier CP, Reiber C. Drugs and sexual effects: role of drug type and gender. J Subst Abuse Treat 2002; 22: 103-108.

8. Rawson RA, Gonzales R, Pearce V, Ang A, Marinelli-Casey P, Brummer J. Methamphetamine dependence and human immunodeficiency virus risk behavior. J Subst Abuse Treat 2008; 35: 279-284.

9. Abdool Karim, SS, Churchyard GJ, Abdool Karim Q, Lawn SD. HIV infection and tuberculosis in South Africa: an urgent need to escalate the public health response. The Lancet 2009; 374: 921-933.

10. Wechsberg W, Jones HE, Zule WA, Myers BJ, Browne FA, Kaufman MR, Luseno L, Flisher AJ, Parry CDH. Methamphetamine ('tik') use its association with condom use among out-of school females in Cape Town, South Africa. Am J Drug Alcohol Abuse 2010; 36: 208-213.

11. Wechsberg WM, Luseno WK, Karg RS, Young S, Rodman N, Myers B, Parry CDH. Alcohol, cannabis, and methamphetamine use and other risk behaviours among Black and Coloured South African women: A small randomized trial in the Western Cape. Int J Drug Policy 2008; 19: 130-139.

12. Simbayi LC, Kalichman SC, Cain D, Cherry C, Nomvo H, Cloete A. Methamphetamine use and sexual risks for HIV infection in Cape Town, South Africa. J Subs Use 2006; 11: 291-300.

13. Kalichman SC, Simbayi LC, Vermaak R, Jooste S, Cain D. HIVIAIDS risks among men and women who drink at informal alcohol serving establishments (Shebeens) in Cape Town, South Africa. Prev Sci 2008; 9: 55-62.

14. Parry CDH, Carney T, Petersen P, Dewing S. Drug use and sexual HIV risk patterns among non-injecting and injecting drug users in Cape Town, Pretoria and Durban, South Africa (MRC Technical Report). Parow: Medical Research Council, 2007.

15. Sawyer-Kurian KM, Wechsberg WM, Luseno W. Exploring the differences and similarities between Black/African and Coloured men regarding violence against women, substance abuse, and HIV risks in Cape Town, South Africa. Psychol Men Masc 2009; 10: 13-29.

16. Shisana O, Rehle T, Simbayi LC, Zuma K, Jooste S, Pillay-van Wyk V, Mbelle $N$, van Zyl J, Parker W, Zungu NP, Pezi S, the SABSSM III Implementation Team. South African nation HIV prevalence, incidence behaviour and communication survey 2008: A turning tide among teenagers? Cape Town. HSRC Press, 2009.

17. Parry CDH, Petersen P, Carney T, Needle R. Opportunities for enhancing and integrating HIV and drug services for drug using vulnerable populations in South Africa. Int J Drug Policy 2010; 21: 289-295. 